2. To: (Receiving Organization) Distribution

5. Proj./Prog./Dept./Div.:

Phase I Feed Composition

Data/Waste

Management/DA\&I/Process

Engineering

8. Originator Remarks:

This document is being released into the supporting document system for retrievability purposes.

11. Receiver Remarks: 11A. Design Basel ine Document? [] Yes [X] No For release.
3. From: (Originating Organization) Data Assessment and Interpretation

6. Design Authority/ Design Agent/Cog.

Paul J. Certa
4. Related EDT No.

$\mathrm{N} / \mathrm{A}$

7. Purchase Order No.:

$$
N / A
$$

9. Equip./Component No.:

$$
\mathrm{N} / \mathrm{A}
$$

10. System/Bidg./Facility: $\mathrm{N} / \mathrm{A}$

12. Major Assm. Dwg. No.: $N / A$

13. Permit/Permit Application No.: $N / A$

14. Required Response Date: 04/20/99

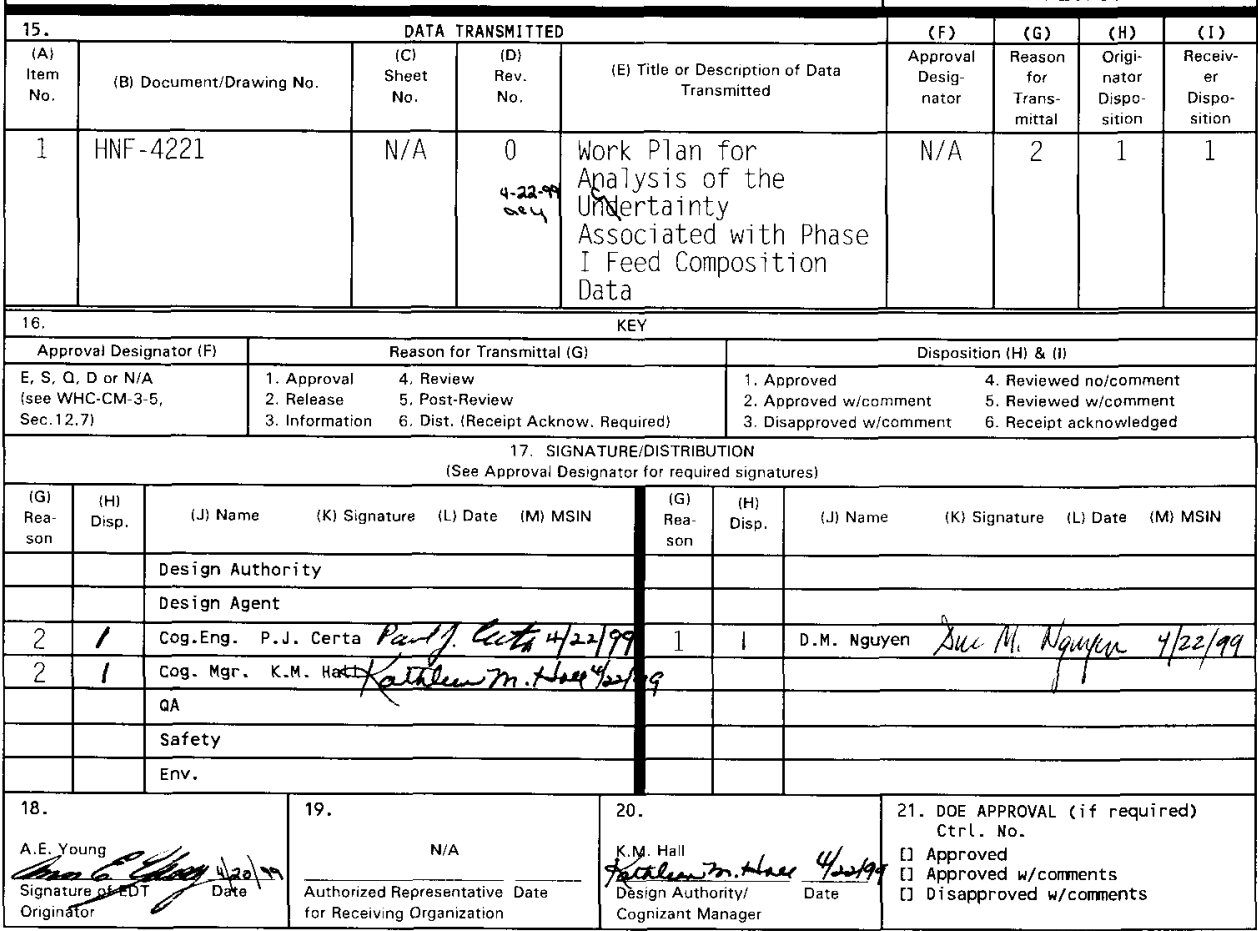

BD-7400-172-2 (05/96) GEF097 


\section{Work Plan for Analysis of the Uncertainty Associated with Phase I Feed Composition Data}

Duc M. Nguyen

Lockheed Martin Hanford, Corp., Richland, WA 99352

U.S. Department of Energy Contract DE-AC06-96RL13200

EDT/ECN: EDT611461/ UC: 2070

Org Code: 74B20 CACN/COA: 106427/BA10

B\&R Code: EW 3120074 Total Pages: 18

Key Words: Work Plan. Uncertainty Analysis. Analysis. Phase I. Feed Envelopes, Feed Composition, Probability Evaluation, Feed Delivery, Privatization Contract

Abstract: N/A

TRADEMARK DISCLAIMER. Reference herein to any specific comercial product, process, or service by trade name, trademark, manufacturer, or otherwise, does not necessarily constitute or imply its endorsement, recormendation, or favoring by the United States Government or any agency thereof or $i$ ts contractors or subcontractors.

Printed in the United States of America. To obtain copies of this document, contact: Document Control Services, P.O. Box 950, Mailstop H6-08, Richland WA 99352, Phone (509) 372-2420;

Fax (509) 376-4989.
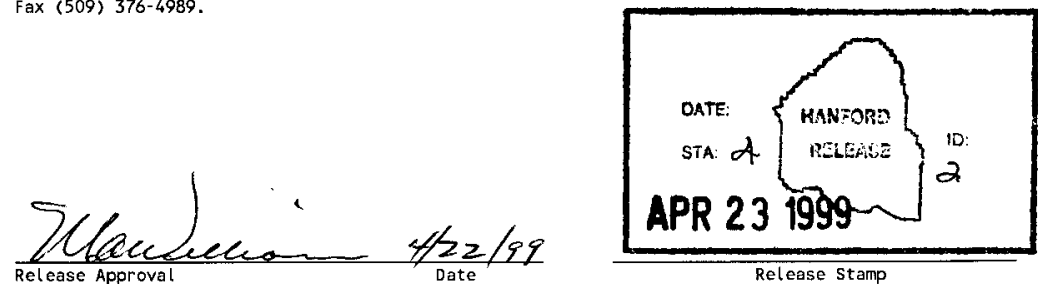

Release Stamp

Approved for Public Release 
HNF-4221

Revision 0

\section{WORK PLAN FOR ANALYSIS OF THE UNCERTAINTY ASSOCIATED WITH PHASE 1 FEED COMPOSITION DATA}

D. M. Nguyen

Lockheed Martin Hanford Corporation

Date Published

April 1999

Prepared for the U. S. Department of Energy

Assistant Secretary for Environmental Management

Project Hanford Management Contractor for the

U.S. Department of Energy under Contract DE-AC06-96RL13200

Approved for public release; distribution is unlimited 


\section{TABLE OF CONTENTS}

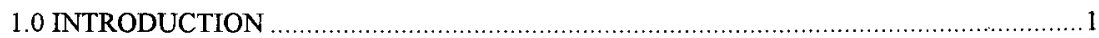

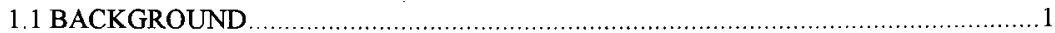

1.2 PURPOSE

1.3 SCOPE.

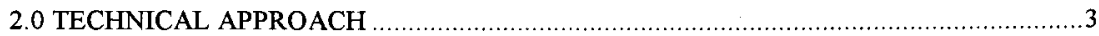

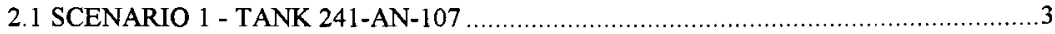

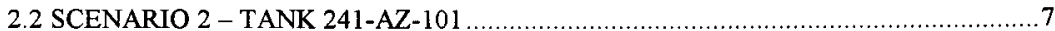

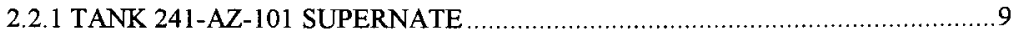

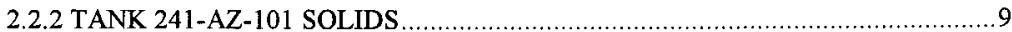

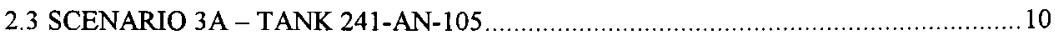

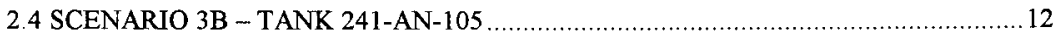

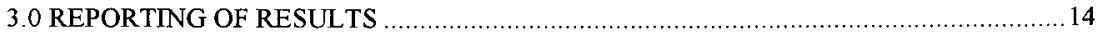

4.0 DELIVERABLES

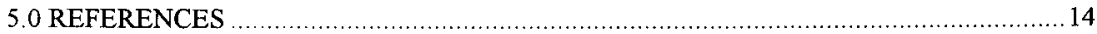

\section{LIST OF FIGURES}

Figure 1. Feed Delivery Scheme for Tank 241-AN-107 Waste ......................................... 4

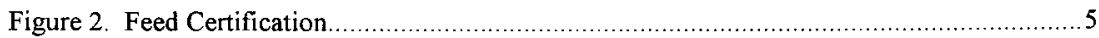

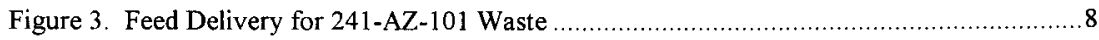

Figure 4. Feed Delivering Scheme for Tank 241-AN-105 Waste (Scenario 3A) ......................11

Figure 5. Feed Delivering Scheme for Tank 241-AN-105 Waste (Scenario 3B) ...................... 13 


\section{HNF-4221 Rev. 0}

\section{LIST OF TERMS}

DOE

DOE-RL

ESP

HLW

ICD

LAW

PHMC

TWRS

$\%$
The U.S. Department of Energy

U.S. Department of Energy, Richland Operations Office

Environmental Simulation Program

high-level waste

interface control document

low-activity waste

Project Hanford Management Contract

Tank Waste Remediation System

percent 


\section{WORK PLAN FOR ANALYSIS OF THE UNCERTAINTY ASSOCIATED WITH PHASE I FEED COMPOSITION DATA}

\subsection{INTRODUCTION}

\subsection{BACKGROUND}

The U.S. Department of Energy-Richland Operations Office (DOE-RL) has initiated Phase 1 of a two-phase privatization strategy for treatment and immobilization of radioactive waste that is currently managed by the Hanford Tank Waste Remediation System (TWRS) Project. In this strategy, the U.S. Department of Energy (DOE) will purchase services from a contractor-owned and operated facility under a fixed price. The Phase 1 TWRS privatization contract requires that the Project Hanford Management Contract (PHMC) contractors, on behalf of DOE, deliver waste feed in specified quantities and composition to the Privatization Contractor (DOE-RL 1996). The quantity and composition of each feed batch will be certified prior to delivery. Certification sampling schemes for low-activity waste (LAW) and high-level waste (HLW) feeds are described in the interface control documents (ICD-19 and ICD-20, respectively) (BNFL 1998a and $b$ ).

In the event DOE identifies feed that is out of specification based on certification data, Special Contract Requirement $\mathrm{H} .43$ will be invoked. Under this requirement, DOE and the Contractor will negotiate additional cost for processing out of specification feed based on the incremental impacts to the Contractor. Therefore, it is desirable to evaluate whether or not the proposed certification scheme can accurately determine the composition of a feed batch.

\subsection{PURPOSE}

The purpose of this study is to estimate the probability, based on current knowledge, that feed certification data will correctly determine if the composition of a staged feed batch is within the contract specification. Results of the study will be used as a basis for (1) accepting the proposed feed certification methods and procedures in ICD-19 and ICD-20 or recommending changes and (2) estimating the probability that the feed composition exceeds the envelope limits, thereby invoking Requirement $\mathrm{H.43}$ of the contract. In addition, the study will determine how far the feed composition is likely to deviate from the specification. This information could be used to prepare for the negotiations discussed in Requirement H.43. 


\subsection{SCOPE}

The TWRS Privatization Contract specifies four sets of limits (envelopes) for waste feed: A, B, $C$, and D. For this study, wastes in three tanks were chosen to represent the feed envelopes specified in the contract. The selected tanks are 241-AN-107 (representing Envelope C), 241 AN-105 (representing Envelope A), and 241-AZ-101 (the supernate representing Envelope A, B, or $\mathrm{C}$ and the solids representing Envelope D).

At this time, the operating scenarios for delivering the waste in these tanks to the Privatization Contractor are still being refined. For this study, the feed delivery schemes are assumed to be as follows:

1. Supernate from tank $241-\mathrm{AN}-107$ will be decanted to an intermediate staging tank (either 241-AP-102 or 241-AP-104). The staged waste will be delivered to the Contractor when requested.

2. Waste in tank 241-AZ-101 will be mixed and the slurry transferred to the Privatization Contractor.

3. Two waste staging schemes for tank 241-AN-105 waste will be evaluated for comparison:

a. Homogenizing the waste in tank 241-AN-105 and transferring the homogeneous waste to tanks 241-AP-102 and 241-AP-104, and

b. Decanting the supernate in tank 241-AN-105 to either staging tank 241-AP-102 or 241-AP-104, dissolving the sludge in 241-AN-105, and transferring the resulting slurry into the other available staging tank

For each scenario, this study will:

- Estimate the true concentration of each waste component in the staged feed using source tank waste data, feed delivery process test results, equipment test results,

- Evaluate the probability that the estimates of the true concentrations will exceed applicable feed envelope limits

- Evaluate the probability that the waste concentrations, as measured by feed certification, exceed the applicable feed envelope limits.

This work plan describes the technical approach for performing the uncertainty analysis. A brief description of the expected results of and deliverables for the study is also provided. It should be noted that this work plan is developed as a general guide for the uncertainty evaluation. The technical approach and anticipated results may be refined (and possibly modified) based on new 
information. Deviations from this work plan will be discussed with Waste Feed Delivery prior to implementation.

\subsection{TECHNICAL APPROACH}

For each scenario, an uncertainty analysis will be performed for every waste component that has a corresponding feed envelope limit. Monte Carlo simulation will be used to estimate the probabilities that (1) the true concentration of the component in the staged feed will exceed the limit, (2) the concentration as measured by certification will exceed the limit, and (3) the homogeneity of the mixed staged feed, as indicated by feed certification data, is acceptable. The technical approaches for the four feed delivery scenarios are described below.

\subsection{SCENARIO 1 - TANK 241-AN-107}

The waste in tank 241-AN-107 is expected to be the first LAW to be treated and immobilized by the Privatization Contractor. The feed delivery and certification schemes for this waste (shown in Figures 1 and 2, respectively) can be summarized as follows:

1. Decant and transfer the supernate (i.e., soluble fraction) to an intermediate staging tank (241-AP-102 or 241-AP-104). Dilute the supernate as it is being transferred. Prior to receiving the waste, each staging tank is expected to contain approximately 30,000 gallons of flush water (and insoluble solids from the waste previously stored in the tank).

2. Mix waste in the staging tank;

3. Collect nine samples and analyze them for sodium, aluminum, and cesium-137;

4. Test the homogeneity of the waste by verifying that the variability in the samples is equal or less than $20 \%$;

5. Prepare one composite sample from the nine grab samples;

6. Prepare three sub-samples from the composite sample and analyze for all required waste components.

7. Estimate the mean concentrations from the three sub-samples and compare to the envelope limits.

8. Transfer the waste as Envelope $\mathrm{C}$ feed to the Privatization Contractor. 
HNF-4221 Rev. 0
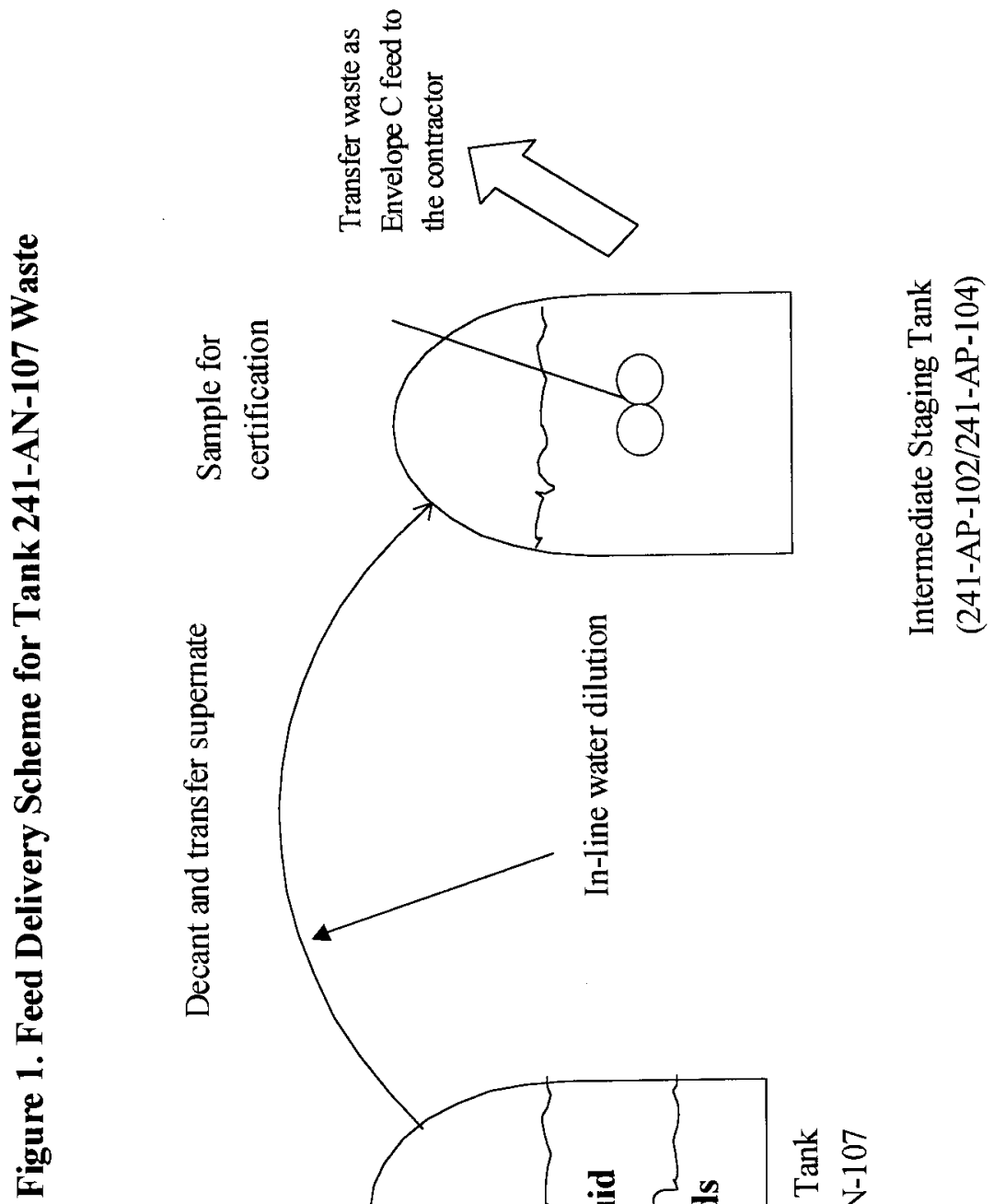

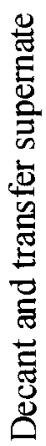

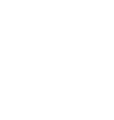


HNF-4221 Rev. 0

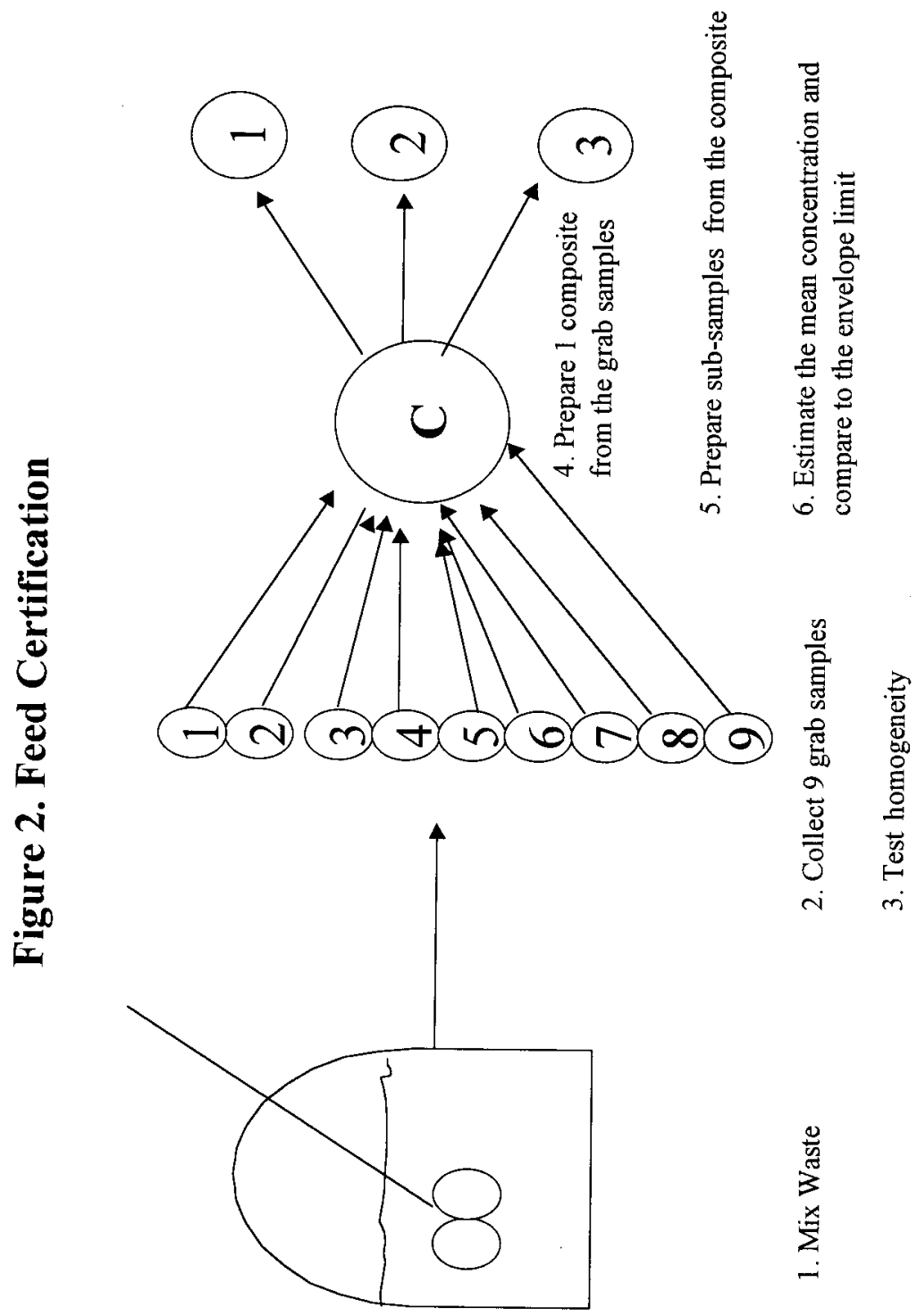


Tank 241-AN-107 contains low-activity waste (LAW). Feed envelope limits for LAW are specified in terms of moles (for chemicals) or Becquerels (for radionuclides) per mole of sodium (Na). The probability that the concentration of a waste component will exceed the envelope limit can be written as:

$$
P\left\{\frac{[\text { Component }]_{F T}}{[N a]_{F T}} \leq \text { Limit }\right\}
$$

Where FT represents properties of waste in the staging tank.

The Monte Carlo simulation that will be used to determine the probabilities consists of a very large number of iterations. The calculations to be performed in each iteration are as follows:

An estimate of the true concentration in the staged waste will be randomly from the following range of values:

$$
\left(x_{o} \pm s_{o}\right)(D F)(M F)
$$

Where $\mathrm{x}_{\mathrm{o}}$ and $\mathrm{s}_{\mathrm{o}}$ are the concentration and the associated variance in the source tank. DF and MF are dilution and mixing factors, respectively.

The calculated true concentration, along with an estimated variance, $s_{H}$ (discussed further below), will be used to predict concentrations of the component in the nine certification grab samples. Homogeneity of the waste will be determined and tested for acceptance using these concentrations.

The mean concentration of the composite sample will be estimated by averaging the nine values for the grab samples. The composite mean concentration, along with another estimated variance, $\mathrm{s}_{\mathrm{L}}$ (discussed further below), will be used to predict concentrations of the three sub-samples. The three concentrations are averaged, and the estimated mean is compared to the envelope limit.

A large number of iterations (expect to be in the thousands) will be performed. The optimum number of iterations will be determined prior to performing the Monte Carlo calculations. The results of the Monte Carlo calculations will allow a determination of (1) probability that the true concentration of the component will exceed the limit, (2) probability that the concentration as measured by feed certification will exceed the limit, and (3) the likelihood that the waste will fail the homogeneity test due to the component. 
The input data needed for the calculations are:

- The initial mean concentrations and variances for the component and sodium $\left(\mathrm{x}_{\mathbf{0}}, \mathrm{s}_{\mathrm{o}}, \mathrm{x}_{\mathrm{Na}, \mathrm{o}}\right.$, and $\mathrm{s}_{\mathrm{Na}, \mathrm{o}}$ ) will be based on sampling or Best-Basis Inventory results.

- The dilution factor will be based on the current process flowsheet requirements (Environmental Simulation Program (ESP) data). It is anticipated that a single value will be used for this factor. A sensitivity analysis will be performed for values bounding this factor.

- The mixing factor will be based on mixing pump test results. This factor affects the range of values from which the true concentration is randomly selected. Sensitivity analyses, in which the variance based on source tank characterization data is adjusted, will be performed.

- The variability of mixed waste in the staging tank, as represented by $s_{H}$, will be determined from characterization data obtained from grab samples taken from a mixed waste tank (e.g., 1994 data for tank 241-AP-102).

- The variance due to preparation and analysis of the composite and sub-samples, $\mathrm{s}_{\mathrm{L}}$, will be estimated from similar laboratory activities.

\subsection{SCENARIO 2 - TANK 241-AZ-101}

The feed delivery scheme for tank 241-AZ-101 is shown in Figure 3. The liquid and solids in the tank will be mixed using a mixer pump. The waste will be certified using the sampling scheme described previously (See Figure 2 and Steps 2 through 8 in the section above). The waste feed will then be transferred to the Privatization Contractor where the liquid and solids will be treated as LAW and HLW, respectively. Since the envelope limits for these two waste types are specified in different terms, the liquid and solids from this tanks are considered separately in this report.

Although the Privatization Contract indicates that the supernate from tank 241-AZ-101 could be Envelope A, B, or C waste, the liquid will be assumed to meet Envelope B requirements. Preliminary information indicates that the supernate will not meet the Envelope B requirements for a number of waste components. However, it is expected that, in comparison to the other envelopes, more waste components will meet Envelope B requirements. If time permits, calculations using the other envelope limits (i.e., A and/or C) will also be performed. 
HNF-4221 Rev. 0

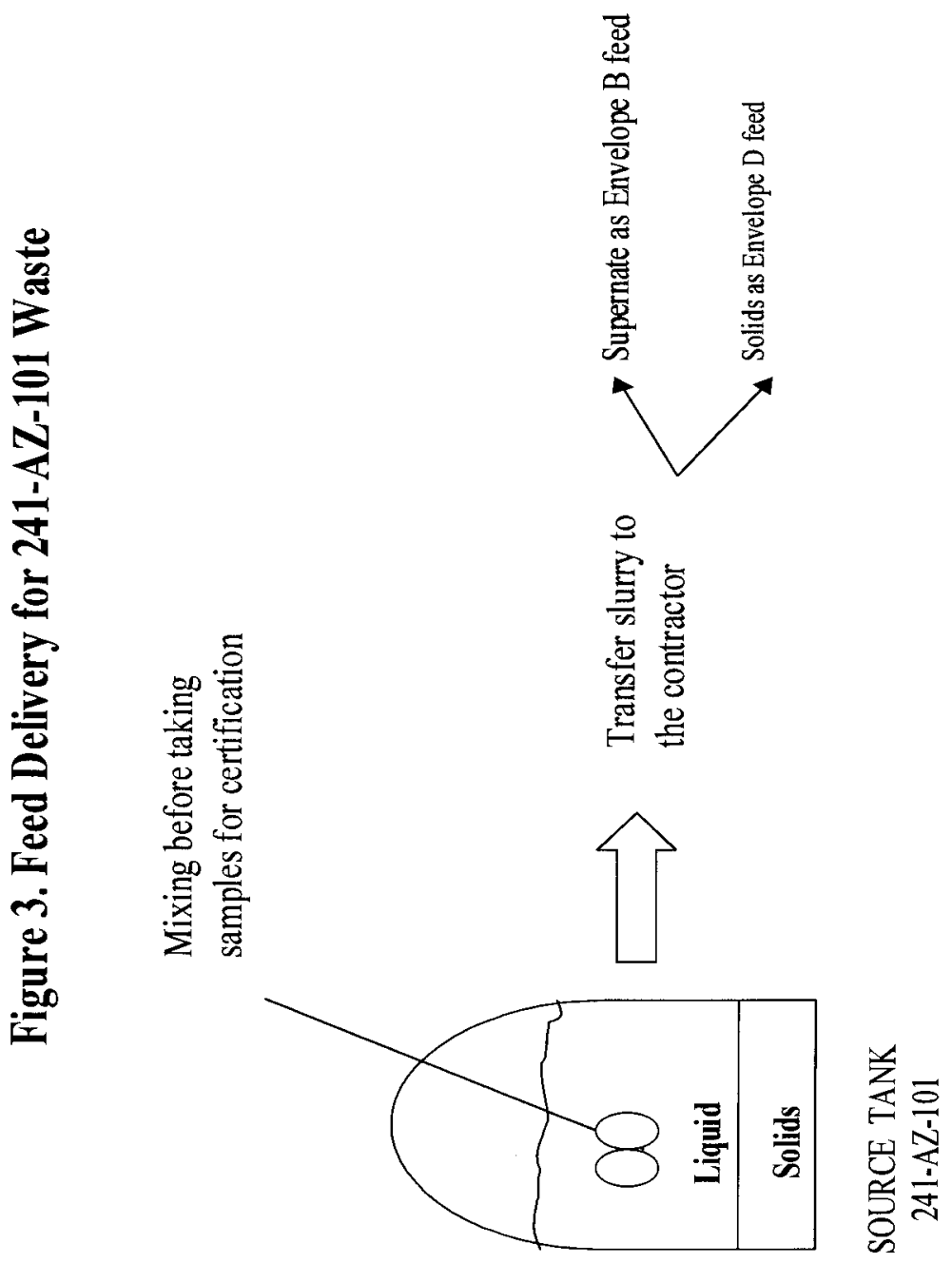




\subsubsection{TANK 241-AZ-101 SUPERNATE}

Based on the feed delivery scheme for tank 241-AZ-101 waste, an estimate of the true concentration in the liquid feed will be randomly selected from the following range of values:

$$
\left(x_{o} \pm s_{o}\right)(H F)(M F)
$$

Where $\mathrm{HF}$ and MF are heating and mixing factors, respectively. The heating factor is due to the energy added to the waste during mixer pump operations.

The remaining Monte Carlo calculations for feed certification are the same as those for tank 241-AN-107. The input data that will be needed for the calculations are:

- The mean concentrations and variances of waste components in the source tank and the mixing factor will be addressed in the same manner described for tank 241-AN-107.

- Heating affects the solubility of a waste component. The increase in temperature will be estimated based on previous mixer pump test results or thermodynamic calculations. The heating factor for each component will be based on solubility data or laboratory process test results. Depending on the quality of solubility data and the confidence in the estimates of final temperature, a sensitivity analysis will be performed as needed.

\subsubsection{TANK 241-AZ-101 SOLIDS}

Feed envelope limits for HLW are specified in terms of grams (for chemical) or Becquerels (for radionuclides) per 100 grams of washed oxides. The probability that concentration of a waste component in the staging tank exceed the envelope limit can be written as:

$$
P\left\{\frac{\left(x_{c} \pm s_{c}\right)}{\sum\left(x_{w o} \pm s_{w o}\right)} X 100 \leq \text { Limit }\right\}
$$

The true concentration of a component (that is not an oxide) in the solids can be randomly selected from the following range of values:

$$
\left(x_{c, o} \pm s_{c, o}\right)(H F)(M F)
$$


And the true concentration of total washed oxides can be selected from:

$$
\sum\left(x_{u o, o} \pm s_{u o, o}\right)(H F)(M F)(W F)
$$

Where $\mathrm{x}_{\mathrm{u} 0, \mathrm{o}}$ and $\mathrm{s}_{\mathrm{uo}, \mathrm{o}}$ are the mean concentration and variance of an unwashed oxides in the source tank and WF is a wash factor.

Two wash factors will be used in the calculations to simulate aqueous and caustic washes. These factors will be determined from previous sludge wash test data or sludge wash simulation (ESP). The remaining Monte Carlo calculations for tank 241-AZ-101 solids are the same as those described in Section 2.1. The sensitivity of the estimated true concentration to each wash factor will be evaluated.

\subsection{SCENARIO 3A - TANK 241-AN-105}

The feed delivery scheme for tank 241-AN-105 under this scenario is shown in Figure 4. The waste will be mixed using a mixer pump. Each half (approximately) of the resulting slurry will be transferred, with in-line water dilution, to the intermediate staging tanks (241-AP-102 or 241AP-104). The waste in the staging tanks will be further diluted as needed to meet sodium limit. The contents of the tanks will be mixed and samples will be taken per the certification scheme described previously. The waste will be transferred as an Envelope A feed to the Privatization Contractor.

Based on the feed delivery scheme, an estimate of the true concentration ratio in the liquid feed can be randomly selected from the following range of values:

$$
\left(x_{o} \pm s_{o}\right)(H F)(M F)(D F)(D I F)
$$

Where DIF is the dissolution factor. A significant fraction of the solids is expected to dissolve due to dilution, heating, and mixing the waste. The heel of flush water in the staging tank will be included in the dilution factor. 
HNF-4221 Rev. 0

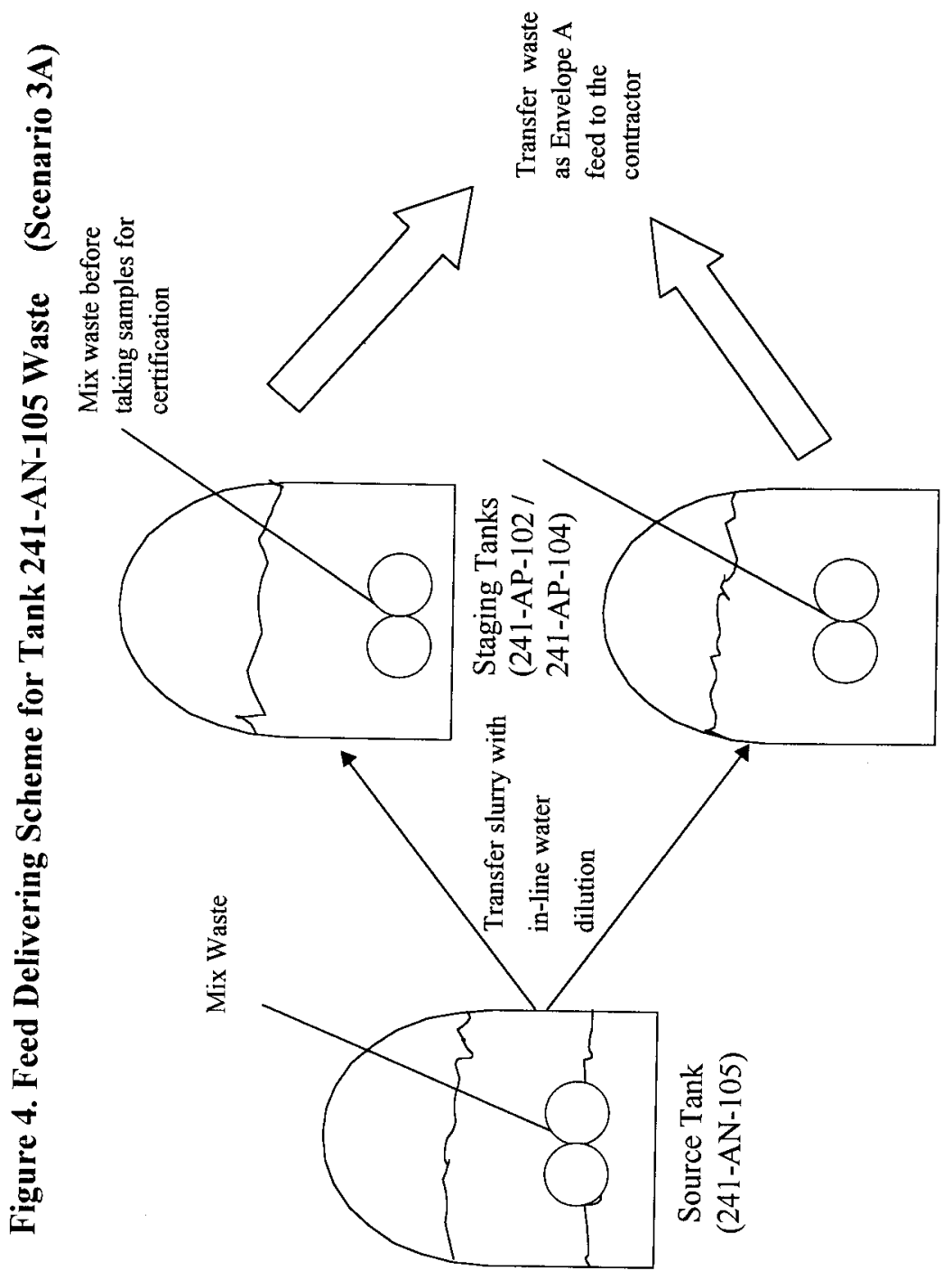


The remaining Monte Carlo calculations for feed certification are the same as those for tank 241-AN-107. The input data that will be needed for the calculations are:

- The mean concentrations and variances of waste components in the source tank, the mixing, heating, and dilution factors will be addressed in the same manner described previously.

- The effect of dissolution on the true concentration will be determined from laboratory dissolution test data and sludge wash simulation (ESP).

In addition, if the waste in tank $241-\mathrm{AN}-105$ is not perfectly mixed prior to being transferred to the staging tanks, the true concentration of a given waste component in the two staging tanks might be different. A sensitivity analysis will be performed to evaluate the impact of this potential difference.

\subsection{SCENARIO 3B - TANK 241-AN-105}

The feed delivery scheme for tank 241-AN-105 under this scenario is shown in Figure 5. The liquid and solids will be transferred to the Contractor via two different paths. The supernate will be decanted and transferred, with in-line dilution, to a staging tank (241-AP-102 or 241-AP-104). The remaining waste will be diluted with water to dissolve soluble solids. The liquid fraction will be decanted and transferred to the other staging tank. The contents of the tanks will be mixed and samples will be taken per the certification scheme described previously. The waste will be transferred as an Envelope A feed to the Privatization Contractor.

The Monte Carlo calculations for each path of waste transfer (i.e., through tank 241-AP-102 or 241-AP-104) are the same as those described in Scenario 3A (Section 2.3). The types of input data required for the calculations are the same. The sources of data are expected to be similar. However, the numerical values of the data for these paths will be different. 


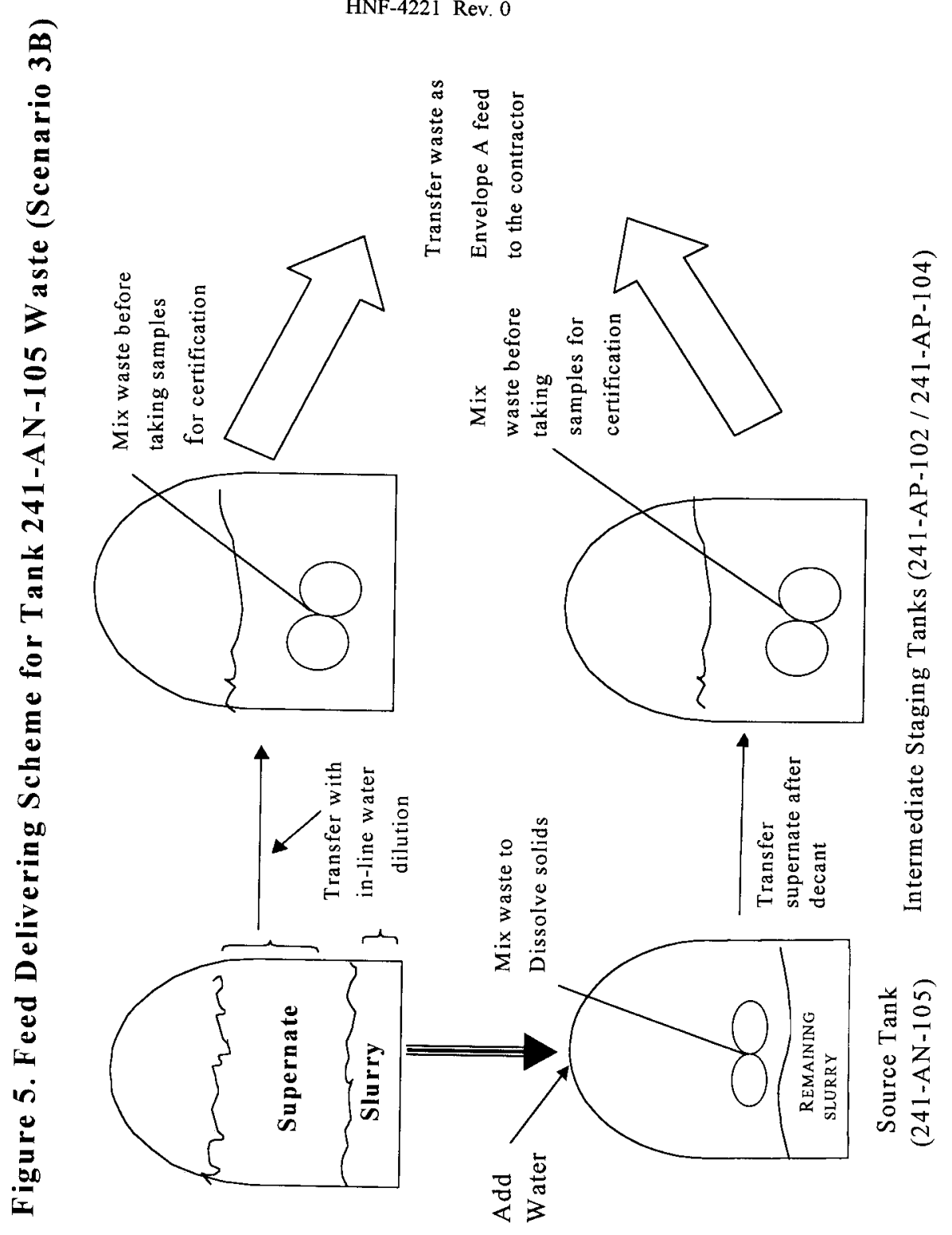


HNF-4221 Rev. 0

\subsection{REPORTING OF RESULTS}

The calculated probabilities for source tank, certification, and combined data will be reported for each of the four scenarios. Results of sensitivity analyses will be evaluated. Data and assumptions used for calculations will be discussed. Conclusions and recommendations based on this analysis will be provided.

For each waste component, plots of (1) cumulative probability versus concentration and (2) cumulative probability versus normalized (to limit) concentration will be provided. The plots will show the envelope limit and percentile where the limit is breached. These plots will be performed for the true and measured concentrations.

The cumulative probability curves for normalized true and measured concentrations will be overlaid to illustrate the uncertainty due to the certification scheme. The probabilities that the true and measured concentrations will exceed the limits will also be cross-tabulated to further show this uncertainty.

In addition, the probabilities calculated for Scenarios $3 \mathrm{~A}$ and $3 \mathrm{~B}$ will be compared. A preferred feed delivery scheme for tank 241-AN-105 waste will be recommended.

\subsection{DELIVERABLES}

A report documenting the results of this study will be provided to the Waste Feed Delivery project by June 23,1999 . At a minimum, this report will contain the information discussed in Section 3.0. Electronic data and results will be provided as requested.

\subsection{REFERENCES}

DOE-RL, 1998, Tank Waste Remediation System Privatization Contract, DE-AC06-96RL13308, Mod. No. A006, U.S. Department of Energy, Richland Operations Office, Richland, Washington.

BNFL, 1998a, Tank Waste Remediation System Privatization Project, Interface Control Document, ICD-19, Between DOE and BNFL Inc. for Low-Activity Waste Feed, BNFL5193-ID-19, Rev. 2, BNFL, Inc., Richland, Washington.

BNFL, 1998b, Tank Waste Remediation System Privatization Project, Interface Control Document, ICD-20, Between DOE and BNFL Inc. for High-Level Waste Feed, BNFL5193-ID-19, Rev. 2, BNFL, Inc., Richland, Washington. 
DISTRIBUTION SHEET

\begin{tabular}{|c|c|c|c|c|c|}
\hline \multirow{2}{*}{$\begin{array}{l}\text { To } \\
\text { Distribution }\end{array}$} & \multirow{2}{*}{\multicolumn{3}{|c|}{ Interpretation }} & \multicolumn{2}{|c|}{ Page 1 of $\not \mid l$ too $\pi$} \\
\hline & & & & \multicolumn{2}{|c|}{ Date $\quad 04 / 20 / 99$} \\
\hline \multicolumn{4}{|c|}{ Project Title/Work Order } & \multicolumn{2}{|c|}{ EDT No. EDT-611461 } \\
\hline \multicolumn{4}{|c|}{$\begin{array}{l}\text { HNF-4221. Rev. 0. "Work Plan for Analysis of the Uncertainty } \\
\text { Assocated with Phase I Feed Composition Data" }\end{array}$} & \multicolumn{2}{|c|}{ ECN No. N/A } \\
\hline Name & MSIN & $\begin{array}{c}\text { Text } \\
\text { with } \\
\text { Al } \\
\text { Attach. }\end{array}$ & Text Only & $\begin{array}{l}\text { Attach./ } \\
\text { Appendix } \\
\text { Only }\end{array}$ & $\begin{array}{l}\text { EDT/ECN } \\
\text { Only }\end{array}$ \\
\hline
\end{tabular}

U. S. Department of Energy -

Richland Field office

DOE/RL Reading Room

H2-53 $\quad x$

COGEMA

L. J. Fergestrom

R3-73 $\quad X$

Lockheed Martin Hanford Corp.

K. M. Ha 7 ?

D. M. Nguyen

S. R. Wi marth

T.C.S.R.C.

R2 - 12 X

$R 2-12 \quad x$

R2 $-12 \quad x$

RI $-10 \quad X$

Lockheed Martin Services, Inc.

Central Files

B1-07 X

Numatec Hanford Corporation

P. J. Certa

D. L. Herting

R3-73 $x$

R. S. Wittman

T6-07

R3-73

$x$
$x$

Protection Technology Hanford

T. L. WeTsh

T4 $-40 \quad X$ 